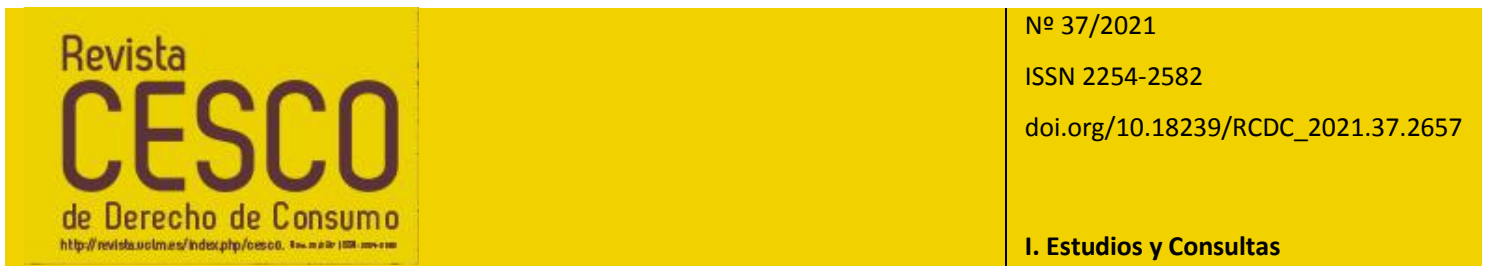

\title{
¿EL REAL DECRETO-LEY 37/2020 IMPIDE LOS DESAHUCIOS DURANTE EL ESTADO DE ALARMA?*
}

\author{
Lucía del Saz Domínguez \\ Centro de Estudios de Consumo \\ Universidad de Castilla- La Mancha
}

Title: Is allowed to practice an eviction during the alarm state once the Royal Decreelaw $37 / 2020$ has entered into force?

Resumen: Comentario de las normas introducidas en materia de desahucios por el Real Decreto-ley 37/2020, de 22 de diciembre, de medidas urgentes para hacer frente a las situaciones de vulnerabilidad social y económica en el ámbito de la vivienda y en materia de transportes.

Palabras clave: suspensión, desahucio, lanzamiento, estado de alarma, arrendamiento, ocupación ilegal.

Abstract: Commentary about the rules introduced in the matter of evictions by Royal Decree-Law 37/2020, of December 22, on urgent measures to deal with situations of social and economic vulnerability in the field of housing and in the field of transports.

Key words: suspension, evictions, launch, state of alarm, leasing, illegal occupation.

SUMARIO: 1. Introducción. 2. La suspensión del procedimiento de desahucio y lanzamiento arrendaticios sin alternativa habitacional. 2.1. ¿Afecta a juicios que pretenden el lanzamiento, como parece decir el artículo 1.1 o también a los juicios verbales que sólo solicitan una condena al pago de la renta, sin resolución/desahucio? 2.2. Requisitos para la suspensión. 2.3. ¿Y si llegado el 9 mayo no se ha tomado ninguna medida social o no se ha emitido el informe social? 2.4. ¿Puede pedir suspensión quien ya la hubiera pedido y obtenido con el RD-ley 11/2020? 3.

\footnotetext{
* Trabajo realizado en el marco del Contrato con referencia 2020-COB-10063 financiado con la Ayuda para la financiación de actividades de investigación dirigidas a grupos de la UCLM Ref.: Ref.: 2020-GRIN-29156, denominado "Grupo de Investigación del Profesor Ángel Carrasco" (GIPAC) y en el marco del Proyecto de Investigación PGC2018-098683-B-I00, del Ministerio de Ciencia, Innovación y Universidades (MCIU) y la Agencia Estatal de Investigación (AEI) cofinanciado por el Fondo Europeo de Desarrollo Regional (FEDER) titulado "Protección de consumidores y riesgo de exclusión social" dirigido por Ángel Carrasco Perera y Encarna Cordero Lobato y a la Ayuda para la realización de proyectos de investigación científica y transferencia de tecnología, de la Junta de Comunidades de Castilla-La Mancha cofinanciadas por el Fondo Europeo de Desarrollo Regional (FEDER) para el Proyecto titulado "Protección de consumidores y riesgo de exclusión social en Castilla-La Mancha" (PCRECLM) con Ref.: SBPLY/19/180501/000333 dirigido por Ángel Carrasco Perera y Ana Isabel Mendoza Losana.
} 
Suspensión durante el estado de alarma del procedimiento de desahucio y de los lanzamientos para personas económicamente vulnerables sin alternativa habitacional en los supuestos de los apartados $2 .^{\circ}, 4 .^{\circ}$ y $7 .^{\circ}$ del artículo 250.1 de la Ley $1 / 2000$, de 7 de enero, de Enjuiciamiento Civil. 3.1. Aspectos relevantes. 4. Bibliografía.

\section{Introducción}

En esta publicación vamos a realizar un comentario de las normas introducidas en materia de desahucios por el Real Decreto-ley 37/2020, de 22 de diciembre, de medidas urgentes para hacer frente a las situaciones de vulnerabilidad social y económica en el ámbito de la vivienda y en materia de transportes, con el que trataremos de clarificar tales novedades y que este breve trabajo resulte útil tanto a los poseedores que hayan iniciado un procedimiento de desahucio -en términos generales $^{1}$ - (o se vean obligados a ello), que se encuentran con la incertidumbre de si es posible su continuación durante el estado de alarma, como para aquellas personas económicamente vulnerables sin alternativa habitacional que puedan beneficiarse de las medidas.

Como se indica en su Exposición de Motivos, estas medidas -entre las que cabe mencionar "la introducción de un periodo de suspensión ${ }^{2}$ del procedimiento de desahucio y de los lanzamientos, cuando afecten a arrendatarios vulnerables sin alternativa habitacional"- se instauran para "ofrecer respuesta inmediata a la grave situación de aquellas personas y hogares que están experimentando con mayor crudeza los efectos de la pandemia (...) y que se enfrentan a situaciones en las que uno de los derechos básicos como es la vivienda, corre serio peligro".

\footnotetext{
${ }^{1}$ Como lo hace notar CORDÓN MORENO en una publicación del mes de abril de 2020 que, aunque en relación al artículo 1 del Real Decreto Ley 11/2020, resulta plenamente aplicable al tema que nos concierne (si bien, debemos añadir la posible suspensión de aquellos supuestos de desahucio por precario, novedad fundamental del Real Decreto-ley 37/2020), "el legislador está pensando en el proceso de desahucio con la nueva técnica monitoria que, según el artículo 440.3 de la Ley de Enjuiciamiento Civil (LEC), se aplica exclusivamente cuando «se ejercite la pretensión de desahucio por falta de pago de rentas o cantidades debidas (...)». Pero (...) atendida la finalidad de la norma, debe entenderse que la suspensión afectará también a los otros procesos de desahucio previstos en la ley que pueden terminar con la resolución del contrato de arrendamiento y, en consecuencia, con el lanzamiento del arrendatario". CORDÓN MORENO, F.J.: «Real Decreto Ley 11/2020, de 31 de marzo. Suspensión del procedimiento de desahucio y de los lanzamientos», Gómez-Acebo \& Pombo, abril 2020, disponible en: https://www.gap.com/publicaciones/real-decreto-ley-11-2020-de-31-de-marzo-suspension-del-procedimiento-dedesahucio-y-de-los-lanzamientos/ Ahora ciertamente para delimitar el ámbito de aplicación material de la norma se mencionan "los juicios verbales que versen sobre reclamaciones de renta o cantidades debidas por el arrendatario, o la expiración del plazo de duración de contratos suscritos conforme a la Ley 29/1994, de 24 de noviembre, de Arrendamientos Urbanos, que pretendan recuperar la posesión de la finca, se haya suspendido o no previamente el proceso en los términos establecidos en el apartado 5 del artículo 441 de dicha ley", así como "todos los juicios verbales en los que se sustancien las demandas a las que se refieren los apartados $2 .^{\circ}, 4 .^{\circ}$ y $7 .^{\circ}$ del artículo 250.1 de la Ley $1 / 2000$, de 7 de enero, de Enjuiciamiento Civil".

2 Dicho periodo se extiende desde la entrada en vigor del presente Real Decreto-ley hasta la finalización del estado de alarma declarado por el Real Decreto 926/2020, de 25 de octubre, por el que se declara el estado de alarma para contener la propagación de infecciones causadas por el SARS-CoV-2, prorrogado por Real Decreto 956/2020, de 3 de noviembre.
} 
Guiado por el propósito apuntado, el citado texto normativo dedica su Capítulo I (bajo el título "Medidas en materia de vivienda") a esta cuestión, con un artículo (Artículo 1) que se subdivide en dos apartados. Así, realiza una distinción en función de la existencia o ausencia de justo título por el que las personas accedieron a las viviendas (mientras que el apartado primero atiende a la suspensión de los procedimientos de desahucio arrendaticios, el apartado segundo contiene la posibilidad de suspender durante el estado de alarma el procedimiento de desahucio y de los lanzamientos de los ocupantes ilegales de inmuebles ${ }^{3}$ ).

A continuación procederemos a glosar el artículo 1 del Real Decreto-ley 37/2020, estructurando el comentario en dos puntos principales a fin de respetar la mentada distinción.

\section{La suspensión del procedimiento de desahucio y lanzamiento arrendaticios ${ }^{4}$ sin alternativa habitacional}

El artículo 1 modifica el Real Decreto-ley 11/2020, incorporando en su artículo 1.1 la oportunidad de instar la suspensión ${ }^{5}$ extraordinaria del desahucio o lanzamiento por parte del arrendatario que se encuentre "en una situación de vulnerabilidad económica que le imposibilite encontrar una alternativa habitacional" (mediante un incidente de suspensión extraordinaria del desahucio o lanzamiento ante el Juzgado).

El principal problema de esta solución legal es que podría interpretarse como una suspensión automática de todos los procedimientos de desahucio, máxime cuando en el texto cuyo análisis nos ocupa se señala que "así mismo, si no estuviese señalada fecha para el lanzamiento, por no haber transcurrido el plazo de diez días a que se refiere el artículo 440.3 o por no haberse celebrado la vista, se suspenderá dicho plazo o la celebración de la vista". Sin embargo, de su propio emplazamiento -el regulador ubicó esta norma inmediatamente a continuación de la facultad de la persona arrendaticia a instar la suspensión del lanzamiento- extraemos que, también en este supuesto, ha de mediar una petición expresa por parte del arrendatario. Además, con motivo de su carácter excepcional, este precepto ha de interpretarse con carácter restrictivo.

\footnotetext{
3 Concretamente se hace referencia a las personas económicamente vulnerables sin alternativa habitacional contra las que se hayan iniciado los procedimientos previstos en los apartados $2 .{ }^{\circ}, 4 .^{\circ}$ y $7.0^{\circ}$ del artículo 250.1 de la Ley $1 / 2000$, de 7 de enero, de Enjuiciamiento Civil, con motivo del ejercicio de las acciones que en vía civil protegen frente a la ocupación ilegal de inmuebles (la acción de desahucio por

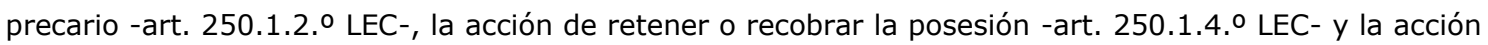
para la protección de los derechos reales inscritos -art. 250.1.7.0 LEC-), empleando los siguientes términos: "Desde la entrada en vigor del presente real decreto-ley y hasta la finalización del estado de alarma (...) en todos los juicios verbales en los que se sustancien las demandas a las que se refieren los apartados $2 .^{\circ}, 4 .^{\circ}$ y $7.0^{\circ}$ del artículo 250.1 de la Ley $1 / 2000$, de 7 de enero, de Enjuiciamiento Civil, el Juez tendrá la facultad de suspender el lanzamiento hasta la finalización del estado de alarma (...)" (artículo 1 bis. 1 del Real Decreto-ley 11/2020, de 31 de marzo, por el que se adoptan medidas urgentes complementarias en el ámbito social y económico para hacer frente al COVID-19).

${ }^{4}$ Es decir, ha de haber mediado la existencia de un contrato de arrendamiento.

${ }^{5}$ Dicha suspensión se alzará, en todo caso, en cuanto finalice el estado de alarma.
} 

o también a los juicios verbales que sólo solicitan una condena al pago de la renta, sin resolución/desahucio?

Con base en el artículo 1.1, atendiendo asimismo al contexto jurídico donde se halla y, lo que es más decisivo, a su espíritu y finalidad, elemento fundamental en la interpretación jurídica, cabe considerar que la normativa examinada solamente resulta aplicable a aquellos juicios que pretendan el "desahucio o lanzamiento", ya que el regulador meramente trata de proteger que las personas en situación de vulnerabilidad económica puedan permanecer en una vivienda (se incide en la imposibilidad de "encontrar una alternativa habitacional para sí y para las personas con las que conviva"). Por ende, los juicios verbales que únicamente solicitan una condena al pago de la renta (sin resolución/desahucio) quedan fuera de su ámbito de aplicación material.

\subsection{Requisitos para la suspensión}

Para que se acuerde la suspensión han de concurrir las siguientes circunstancias:

- El arrendatario deberá acreditar hallarse en alguna de las situaciones de vulnerabilidad económicas establecidas en el artículo 5.1 a) y b) del RDley $11 / 2020^{6}$ - que transcribimos a pie de página para facilitar su lectura-

\footnotetext{
${ }^{6}$ Artículo 5.1 Real Decreto-ley 11/2020, de 31 de marzo: "... a) Que la persona que esté obligada a pagar la renta de alquiler pase a estar en situación de desempleo, Expediente Temporal de Regulación de Empleo (ERTE), o haya reducido su jornada por motivo de cuidados, en caso de ser empresario, u otras circunstancias similares que supongan una pérdida sustancial de ingresos, no alcanzando por ello el conjunto de los ingresos de los miembros de la unidad familiar, en el mes anterior a la solicitud de la moratoria:

i. Con carácter general, el límite de tres veces el Indicador Público de Renta de Efectos Múltiples mensual (en adelante IPREM).

ii. Este límite se incrementará en 0,1 veces el IPREM por cada hijo a cargo en la unidad familiar. El incremento aplicable por hijo a cargo será de 0,15 veces el IPREM por cada hijo en el caso de unidad familiar monoparental.

iii. Este límite se incrementará en 0,1 veces el IPREM por cada persona mayor de 65 años miembro de la unidad familiar.

iv. En caso de que alguno de los miembros de la unidad familiar tenga declarada discapacidad igual o superior al 33 por ciento, situación de dependencia o enfermedad que le incapacite acreditadamente de forma permanente para realizar una actividad laboral, el límite previsto en el subapartado i) será de cuatro veces el IPREM, sin perjuicio de los incrementos acumulados por hijo a cargo.

v. En el caso de que la persona obligada a pagar la renta arrendaticia sea persona con parálisis cerebral, con enfermedad mental, o con discapacidad intelectual, con un grado de discapacidad reconocido igual o superior al 33 por ciento, o persona con discapacidad física o sensorial, con un grado de discapacidad reconocida igual o superior al 65 por ciento, así como en los casos de enfermedad grave que incapacite acreditadamente, a la persona o a su cuidador, para realizar una actividad laboral, el límite previsto en el subapartado i) será de cinco veces el IPREM.

b) Que la renta arrendaticia, más los gastos y suministros básicos, resulte superior o igual al 35 por cien de los ingresos netos que perciba el conjunto de los miembros de la unidad familiar. A estos efectos, se entenderá por «gastos y suministros básicos» el importe del coste de los suministros de electricidad, gas, gasoil para calefacción, agua corriente, de los servicios de telecomunicación fija y móvil, y las posibles
} 
mediante la presentación de los documentos descritos en el artículo 6.1 del citado texto legal?.

- Por su parte, el arrendador (al que se le dará traslado por el Letrado de la Administración de Justicia -LAJ-, antiguo Secretario Judicial) solamente podrá oponerse (en el plazo de diez días) a la suspensión si se hallase igualmente en situación de vulnerabilidad económica o en riesgo de situarse en ella si se adoptase la medida de suspensión del lanzamiento.

- Tras ello, el LAJ remitirá inmediatamente la documentación obrante en autos a los servicios sociales, que deberán emitir un informe (en el plazo máximo de diez días) valorando la situación de vulnerabilidad y las medidas a adoptar por la Administración.

- Una vez emitido el informe referenciado, el Juez lo valorará junto con la documentación presentada y acordará una de las siguientes decisiones:

- Si considerase acreditada la situación de vulnerabilidad económica del arrendatario (y que, en su caso, no deba prevalecer la vulnerabilidad del arrendador) acordará la suspensión del lanzamiento ${ }^{8}$.

contribuciones a la comunidad de propietarios, todos ellos de la vivienda habitual que corresponda satisfacer al arrendatario".

7 Artículo 6.1 RD-ley 11/2020: "La concurrencia de las circunstancias a que se refiere el artículo 5 se acreditará por la persona arrendataria ante la persona arrendadora mediante la presentación de los siguientes documentos:

a) En caso de situación legal de desempleo, mediante certificado expedido por la entidad gestora de las prestaciones, en el que figure la cuantía mensual percibida en concepto de prestaciones o subsidios por desempleo.

b) En caso de cese de actividad de los trabajadores por cuenta propia, mediante certificado expedido por la Agencia Estatal de la Administración Tributaria o el órgano competente de la Comunidad Autónoma, en su caso, sobre la base de la declaración de cese de actividad declarada por el interesado.

c) Número de personas que habitan en la vivienda habitual:

i. Libro de familia o documento acreditativo de pareja de hecho.

ii. Certificado de empadronamiento relativo a las personas empadronadas en la vivienda, con referencia al momento de la presentación de los documentos acreditativos y a los seis meses anteriores.

iii. Declaración de discapacidad, de dependencia o de incapacidad permanente para realizar una actividad laboral.

d) Titularidad de los bienes: nota simple del servicio de índices del Registro de la Propiedad de todos los miembros de la unidad familiar.

e) Declaración responsable del deudor o deudores relativa al cumplimiento de los requisitos exigidos para considerarse sin recursos económicos suficientes según este real decreto-ley".

${ }^{8}$ Respecto a los efectos de la suspensión del procedimiento objeto de suspensión, en el Real Decreto-ley que venimos analizando se indica que "el auto que fije la suspensión señalará expresamente que, finalizado el estado de alarma, se reanudará automáticamente el cómputo de los días a que se refiere el artículo 440.3 o se señalará fecha para la celebración de la vista y, en su caso, del lanzamiento, según el estado en que se encuentre el proceso", esto es, el procedimiento se paraliza hasta que se finalice el estado de alarma, cuando se reanudarán automáticamente, retomando el iter en el estado en que se encontrase en el momento en que se acordó la suspensión. Además, como mencionaremos más adelante, también puede finalizar la suspensión por satisfacción (o desaparición) de la necesidad habitacional del arrendatario (en este caso) u ocupante por la adopción de medidas de la administración competente. 
- Si entendiese no acreditada la vulnerabilidad del arrendatario, o que debe prevalecer la situación de vulnerabilidad del arrendador, acordará la continuación del procedimiento.

- Por otra parte, si se aplicasen por parte de las Administraciones públicas las medidas indicadas en el informe de servicios sociales u otras adecuadas para satisfacer la necesidad habitacional de la persona en situación de vulnerabilidad que garantizasen su acceso a una vivienda digna, deberá ser comunicado inmediatamente al Tribunal para que se acuerde el levantamiento de la suspensión del procedimiento. En consecuencia, la suspensión finalizará tan pronto como se adopten las medidas por las administraciones competentes y en todo caso cuando finalice el estado de alarma.

2.3. ¿Y si llegado el 9 mayo no se ha tomado ninguna medida social o no se ha emitido el informe social?

A mi parecer, la adopción por parte de las administraciones públicas competentes de las medidas "adecuadas para satisfacer la necesidad habitacional de la persona en situación de vulnerabilidad que garanticen su acceso a una vivienda digna" constituye una condición resolutoria ${ }^{9}$ de la suspensión (que adelanta su fin), puesto que, según se contempla en el Real Decreto-ley 37/2020, la desaparición anticipada de los efectos de la suspensión depende de la adopción de tales medidas por la Administración, de tal forma que, desde que el Juez acuerde mediante auto la suspensión del lanzamiento ("por el tiempo que reste hasta la finalización del estado de alarma"), el procedimiento quedará paralizado (es decir, la suspensión desplegará todos sus efectos), pero éste se reanudará en el caso de que se cumpla la condición ("adoptar las medidas (...) adecuadas para satisfacer la necesidad habitacional de la persona en situación de vulnerabilidad que garanticen su acceso a una vivienda digna"10). Subrayamos que tal condición no tiene por qué darse, es decir, podría llegar el 9 de mayo sin que se haya tomado ninguna medida social, en cuyo caso igualmente concluirá la suspensión del procedimiento de desahucio (las medidas de suspensión "dejarán de surtir efecto"), por tratarse del término fijado en el RD-ley ${ }^{11}$.

Aquí conviene realizar un inciso y apuntar que, en correspondencia con lo plasmado en la Disposición adicional segunda, los arrendadores afectados tendrán derecho a solicitar una compensación si la Administración tres meses después a la fecha de

\footnotetext{
${ }^{9}$ Entendida como un acontecimiento futuro e incierto (no sabemos si se va a producir).

${ }^{10}$ El precepto (art. 1.4 RD-ley 11/2020) sigue así: "Una vez adoptadas dichas medidas la Administración competente habrá de comunicarlo inmediatamente al Tribunal competente, y el Juez deberá dictar en el plazo máximo de tres días auto acordando el levantamiento de la suspensión del procedimiento y el correspondiente lanzamiento".

${ }^{11}$ En virtud del artículo 1 del Real Decreto-ley 37/2020, la redacción de los artículos 1.1 y 1 bis.1 RD-ley 11/2020 especifican que: "Estas medidas de suspensión que se establecen con carácter extraordinario y temporal, en todo caso, dejarán de surtir efecto en cuanto finalice el estado de alarma declarado por Real Decreto 926/2020, de 25 de octubre, prorrogado por Real Decreto 956/2020, de 3 de noviembre".
} 
emisión del informe de los servicios sociales no hubiera adoptado las medidas en él contenidas.

Incluso puede alcanzarse el día 9 de mayo (fin del estado de alarma) sin que se haya emitido el informe social. En este supuesto, ya no podrá acordarse la suspensión del procedimiento, debido a que el Real Decreto-ley central de este comentario dispone que las medidas de suspensión (previstas en el texto legal, no solamente las acordadas en cada caso particular) "dejarán de surtir efecto en cuanto finalice el estado de alarma", por esta razón no es posible que el juez acuerde la suspensión tras dicho momento, puesto que tales medidas serán ineficaces desde su dictado. Entonces llegamos al absurdo de que puede instarse la suspensión del desahucio o lanzamiento desde la entrada en vigor del Real Decreto-ley 37/2020 (22 de diciembre) hasta la finalización del estado de alarma declarado por el Real Decreto 926/2020, de 25 de octubre, por el que se declara el estado de alarma para contener la propagación de infecciones causadas por el SARS-CoV-2, prorrogado por Real Decreto 956/2020, de 3 de noviembre (9 de mayo de 2021), pero en muchos casos no llegará siquiera a ser valorada por el juez.

Otra consecuencia de la falta de emisión del informe social es que en este escenario los arrendadores no tendrán derecho a la citada compensación (ex Disposición adicional segunda RD-ley 37/2020), ya que se incorpora como requisito que transcurran "los tres meses siguientes a la fecha en que se emita el informe de los servicios sociales señalando las medidas adecuadas para atender la situación de vulnerabilidad acreditada facilitando el acceso de las personas vulnerables a una vivienda digna" sin que la administración competente hubiera adoptado tales medidas.

Por otra parte, a pesar de efectuar una lectura pormenorizada de este precepto todavía quedan interrogantes por resolver como qué sucederá con el pago de las rentas en el tiempo pendiente o si existe la posibilidad de ejercer derechos arrendaticios entretanto (como, por ejemplo, reclamar que se realicen mejoras).

\section{4. ¿Puede pedir suspensión quien ya la hubiera pedido y obtenido con el RD-ley} $11 / 2020 ?$

A primera vista, dado que el Real Decreto-ley 37/2020 en su artículo 1 no realiza una exclusión expresa al respecto, parece que el arrendatario podrá presentar nuevamente la solicitud indicada y acreditar que cumple los requisitos económicos actuales (encontrarse en situación de vulnerabilidad económica ${ }^{12}$ ). De hecho, como puede extraerse de su Exposición de Motivos del Real Decreto-ley, se ha producido una extensión del alcance temporal de las medidas para su adaptación a la realidad y evolución de la situación "con objeto de mantener y reforzar la protección de los más vulnerables" (desde 2-4-2020, entre otras medidas de apoyo a los colectivos más vulnerables, se estableció la suspensión de los lanzamientos tras reanudarse los

\footnotetext{
${ }^{12}$ A tales efectos remitimos a los artículos 5.1 a) y b) del RD-ley 11/2020, así como a su artículo 6.1.
} 
plazos procesales suspendidos durante el estado de alarma ${ }^{13}$ ), por lo que, además de su propia redacción, una interpretación teleológica y el carácter tuitivo de la medida respaldan este razonamiento.

Sin embargo, para dar respuesta a este interrogante hemos de acudir a su Disposición transitoria primera (relativa al régimen aplicable a los procedimientos en curso), que en su apartado primero advierte que:

"Las modificaciones introducidas en el artículo 1 del presente real decreto-ley, afectarán a los procedimientos de desahucio que puedan iniciarse desde la entrada en vigor del mismo, así como a aquellos procedimientos que se encuentren en curso en los órganos judiciales, aun cuando ya se hubiera decretado la suspensión conforme a las redacciones anteriores del Real Decreto-ley 11/2020, de 31 de marzo, por el que se adoptan medidas urgentes complementarias en el ámbito social y económico para hacer frente al COVID-19.

No obstante lo anterior, no se aplicará la suspensión prevista en el artículo 1 del referido Real Decreto-ley 11/2020, de 31 de marzo, a aquellos procedimientos de desahucio que se hubieran suspendido conforme a lo previsto en dicho artículo en los que se hubiera acordado la reanudación por quedar acreditada la vulnerabilidad económica del arrendador conforme a lo previsto en el apartado 4 del citado artículo".

Por consiguiente, se contempla expresamente la posibilidad de instar la suspensión de los procedimientos de desahucio "aun cuando ya se hubiera decretado la suspensión conforme a las redacciones anteriores del Real Decreto-ley 11/2020", salvo "que se hubiera acordado la reanudación por quedar acreditada la vulnerabilidad económica del arrendador", lo que significa que solamente podrá pedir la suspensión quien ya la hubiera solicitado y obtenido con el RD-ley $11 / 2020$ si no se hubiera acordado la reanudación del procedimiento por quedar acreditada la vulnerabilidad económica del arrendador.

3. Suspensión durante el estado de alarma del procedimiento de desahucio y de los lanzamientos para personas económicamente vulnerables sin alternativa habitacional en los supuestos de los apartados $2 .^{\circ}, 4 .^{\circ}$ y 7.0 del artículo 250.1 de la Ley 1/2000, de 7 de enero, de Enjuiciamiento Civil

En el apartado segundo del artículo a estudiar, por el que se añade un artículo 1 bis al Real Decreto-ley 11/2020, se alude a la suspensión durante el estado de alarma del procedimiento de desahucio y de los lanzamientos para personas económicamente vulnerables sin alternativa habitacional en los supuestos de los apartados $20^{\circ}, 4 .^{\circ}$ y $7.0^{\circ}$ del artículo 250.1 de la Ley $1 / 2000$, de 7 de enero, de Enjuiciamiento Civil (que se introdujeron en nuestra ley de ritos como remedio frente a las ocupaciones ilegales $\left.{ }^{14}\right)$.

\footnotetext{
13 «Memento práctico Francis Lefebvre Arrendamiento de inmuebles Civil-Fiscal-Procesal», Lefebvre-el Derecho S.A. Actualizado a 20-5-2020. No marginal 10370.

${ }^{14}$ Véase al respecto VALENCIA CUENCA, L.M.: «Respuesta legislativa al fenómeno de ocupación ilegal de viviendas», Centro de Estudios de Consumo (CESCO), julio 2018, disponible en:
} 


\subsection{Aspectos relevantes}

Conviene destacar los siguientes puntos del precepto anotado:

- Este artículo permite "desde la entrada en vigor del presente real decreto-ley y hasta la finalización del estado de alarma" la suspensión del lanzamiento que tendría lugar con motivo de aquellos juicios verbales relativos a los apartados 2.0, $4 .^{\circ}$ y $7.0^{\circ}$ del artículo 250.1 LEC. No obstante, esta posibilidad de suspensión se configura como una "facultad" del Juez. Por tanto, la suspensión ha de ser meramente potestativa ${ }^{15}$. Además, en todo caso la suspensión habrá de levantarse en cuanto finalice el estado de alarma (al igual que se indicaba en el supuesto de la suspensión del procedimiento de desahucio y lanzamiento arrendaticios, al que hemos dedicado el inicio de este comentario).

- Requisitos para poder suspender el lanzamiento, que han de concurrir de manera cumulativa:

- Respecto a la titularidad de las viviendas objeto de litigio, han de pertenecer a personas jurídicas o a personas físicas titulares de más de diez viviendas. Con ello, parece que el regulador intenta no perjudicar a los pequeños propietarios, aunque no duda en suprimir el derecho al disfrute de la posesión de los grandes tenedores y personas jurídicas, mientras que, como manifiesta SAN CRISTÓBAL REALES, "son los servicios sociales los que deben proveer una solución habitacional para las situaciones personales o familiares de vulnerabilidad"16.

\section{Persona que habite la vivienda sin título:}

a) Habrá de ser persona dependiente (de conformidad con lo dispuesto en el apartado dos del artículo 2 de la Ley 39/2006, de 14 de diciembre, de Promoción de la Autonomía Personal y Atención a las

\footnotetext{
http://centrodeestudiosdeconsumo.com/images/Respuesta legislativa al fenomeno de ocupacion ile gal de viviendas.pdf

${ }^{15}$ Ahora bien, ¿qué elementos serán valorados para decretar la suspensión del lanzamiento? El propio texto da respuesta a este interrogante, aunque no establece un listado tasado, sino que se limita a indicar que el Juez para tomar tal decisión tendrá en cuenta, "entre otras que procedan, las siguientes circunstancias:

a) Las circunstancias relativas a si la entrada o permanencia en el inmueble está motivada por una situación de extrema necesidad", señalando que a tal efecto "se valorará adecuadamente el informe de los servicios sociales emitido conforme al apartado siguiente.

b) Las circunstancias relativas a la cooperación de los habitantes de la vivienda con las autoridades competentes en la búsqueda de soluciones para una alternativa habitacional que garantizara su derecho a una vivienda digna".

16 SAN CRISTÓBAL REALES, S.: «Las acciones civiles frente a la ocupación ilegal de inmuebles tras la Ley 5/2018, de 11 de junio». Revista General de Derecho Procesal, no. 46, 2018, p. 2.
} 
personas en situación de dependencia ${ }^{17}$ ), víctima de violencia sobre la mujer o tener a su cargo, conviviendo en la misma vivienda, alguna persona dependiente o menor de edad.

b) Además, deberán acreditar, en todo caso, que se encuentren en situación de vulnerabilidad económica por hallarse en alguna de las situaciones descritas en la letra a) del artículo 5. Seguidamente, el procedimiento se sustanciará tal y como hemos explicado en el caso anterior (apartado 1: La suspensión del procedimiento de desahucio y lanzamiento arrendaticios sin alternativa habitacional, en lo relativo a la emisión del informe por los servicios sociales -con la salvedad de que el plazo máximo para emitir el informe es de quince días, en lugar de los diez días fijados en los desahucios arrendaticios-, valoración del juez, resolución y posible levantamiento de la eventual suspensión si se adoptan medidas por las autoridades competentes).

- A lo que hemos de añadir que el acceso en la vivienda se haya producido con anterioridad a la entrada en vigor del presente real decreto-ley (es decir, antes del 22 de diciembre de $2020^{18}$ ). De este modo, a las ocupaciones producidas a partir del 22 de diciembre de 2020 no les resulta aplicable la posibilidad de suspensión del procedimiento de desahucio, dado que el apartado séptimo del artículo 1 bis del Real Decretoley 37/2020 establece que "en ningún caso procederá la suspensión (...) f) Cuando la entrada en la vivienda se haya producido con posterioridad a la entrada en vigor del presente real decreto-ley". Quizás con esta disposición se pretendía desincentivar o bloquear el fomento de la ocupación que podría producirse con motivo de este Real Decreto-ley, aunque algunos titulares periodísticos o una lectura parcial del texto legal pueden ocasionar confusión y un efecto llamada a la ocupación.

- Tampoco procederá la suspensión en los siguientes supuestos: (i.) si la entrada o permanencia se produjera en el domicilio habitual o segunda residencia debidamente acreditada de una persona física (aunque fuere propietaria de más de diez inmuebles), (ii.) si la persona jurídica tuviere "cedido por cualquier título válido en derecho a una persona física que tuviere en él su domicilio habitual o segunda residencia debidamente acreditada", (iii.) si la entrada o permanencia es consecuencia de un delito, (iv.) cuando indicios racionales de que la vivienda se

\footnotetext{
17 Apartado dos del artículo 2 de la Ley 39/2006, de 14 de diciembre, de Promoción de la Autonomía Personal y Atención a las personas en situación de dependencia: "Dependencia: el estado de carácter permanente en que se encuentran las personas que, por razones derivadas de la edad, la enfermedad o la discapacidad, y ligadas a la falta o a la pérdida de autonomía física, mental, intelectual o sensorial, precisan de la atención de otra u otras personas o ayudas importantes para realizar actividades básicas de la vida diaria o, en el caso de las personas con discapacidad intelectual o enfermedad mental, de otros apoyos para su autonomía personal".

${ }^{18}$ En virtud de su Disposición final segunda este real decreto-ley entrará en vigor el mismo día de su publicación en el «Boletín Oficial del Estado».
} 
esté utilizando para la realización de actividades ilícitas o (v.) si se produjere en inmuebles de titularidad pública o privada destinados a vivienda social que ya se hubieran asignado a un solicitante por parte de la administración o entidad que los gestione.

\section{Bibliografía}

CORDÓN MORENO, F.J.: «Real Decreto Ley 11/2020, de 31 de marzo. Suspensión del procedimiento de desahucio y de los lanzamientos», Gómez-Acebo \& Pombo, abril 2020, disponible en: https://www.ga-p.com/publicaciones/real-decreto-ley-112020-de-31-de-marzo-suspension-del-procedimiento-de-desahucio-y-de-loslanzamientos/

LEFEBVRE-EL DERECHO S.A.: «Memento práctico Francis Lefebvre Arrendamiento de inmuebles Civil-Fiscal-Procesal». Actualizado a 20-5-2020. No marginal 10370.

SAN CRISTÓBAL REALES, S.: «Las acciones civiles frente a la ocupación ilegal de inmuebles tras la Ley 5/2018, de 11 de junio». Revista General de Derecho Procesal, no. 46, 2018, p. 2.

VALENCIA CUENCA, L.M.: «Respuesta legislativa al fenómeno de ocupación ilegal de viviendas», Centro de Estudios de Consumo (CESCO), julio 2018, disponible en: http://centrodeestudiosdeconsumo.com/images/Respuesta legislativa al fenome no de ocupacion ilegal de viviendas.pdf 